\title{
Rapid enamel deposition on Sprague Dawley after nano calcium supplementation during pregnancy
}

\author{
Heriati Sitosari*, Alma Linggar Jonarta*, Yustina Andwi Ari Sumiwi**, Tetiana Haniastuti* \\ *Department of Oral Biology, Faculty of Dentistry, Universitas Gadjah Mada, Yogyakarta, Indonesia \\ **Department of Histology and Cellular Biology, Faculty of Medicine, Public Health and Nursing, Universitas Gadjah Mada, \\ Yogyakarta, Indonesia \\ *JI Denta No 1, Sekip Utara, Yogyakarta, Indonesia; email: heriatisitosari@ugm.ac.id
}

Submitted: $2^{\text {th }}$ July 2018; Revised: $19^{\text {th }}$ August 2018; Accepted: $26^{\text {th }}$ September 2018

\begin{abstract}
Calcium is one of the most important minerals needed during hard tissue development. The preparation of this material into nano-sized particle is carried out to enhance the bioavailability and distribution of calcium in the body. Lack of calcium during odontogenesis causes defect in enamel such as hypoplasia and hypomineralization. During amelogenesis, after secretion of organic matrices, enamel mineralization will start in the presence of calcium. The objective of this study was to determine the effect of nano calcium supplementation during pregnancy on enamel development. In this study, 3-month-old female Sprague Dawley were mated and divided into three groups: nano calcium group (A), micro calcium group (B), and negative control group (C). The treatment was started on day 1 of pregnancy to day 1 after birth by intragastric administration method. The mandibles of 6 pups from each group were collected and stained with hematoxylin and eosin. Examination was conducted using microscope. Enamel deposition was measured using Optilab Image Raster ${ }^{\circledR}$ and the data collected was analyzed using t-test. Histological section of mandibular right first molar on Sprague Dawley newborn pups showed that enamel was observed on day 1 after birth but only on the group treated with nano calcium and micro calcium. Statistical analysis performed showed that the difference between the two groups was significant $(p<0.05)$. From this study it can be concluded that the administration of nano calcium during pregnancy leads to rapid enamel deposition on Sprague Dawley pups.
\end{abstract}

Keywords: nano calcium; tooth development; enamel; amelogenesis; Sprague Dawley

\section{INTRODUCTION}

One of the most important minerals needed in the body is calcium. This mineral can be found easily on regular foods such as dairy products and vegetables. ${ }^{1}$ Calcium is important for bone health as well as muscular contraction, neural regulation, and blood clotting. ${ }^{2}$ This mineral also regulates some cellular activities and signaling in the body such as inducing cellular differentiation. ${ }^{3,4}$

The development of nano-sized particle is carried out to enhance the bioavailability and distribution of that substance in the body. ${ }^{5}$ Nanosized material has different rates of absorption, metabolism, and excretion compared to microsized material. A material can be categorized into a nano particle if it has a dimension less than or equal to $100 \mathrm{~nm}^{6}$
Nano calcium is created to maximize calcium absorption. This product produces a higher release of calcium ions when compared with both macro and micro calcium products. ${ }^{7}$ There is a few evidence for the distribution of nano particle in the body after oral consumption but it has been known that the smallest nano particles have the widest distribution. ${ }^{8,9}$ The distribution and bioavailability of calcium depend on the solubility of products and the presence of substitutes that affect calcium absorption in the body. ${ }^{10}$

During tooth development, calcium is needed and the deficiency of this mineral during odontogenesis causes defect on dental hard tissue such as enamel and dentin. ${ }^{11}$ Enamel has a low tensile strength which causes its brittleness and it also has a high modulus of elasticity which will 
minimize the possibility of fracture when it works simultaneously with dentin. Defects such as enamel hyoplasia and hypomineralization will affect tooth structure. Usually, hypoplasia manifests as pits and grooves on enamel surface and tooth will be more susceptible to caries or dental fracture after eruption. ${ }^{12}$

As the hardest biological tissue, enamel can withstand forces, and very resistant to wear. ${ }^{12,13}$ The principal component of enamel is calcium hydroxyapatite $\mathrm{Ca}_{10}\left(\mathrm{PO}_{4}\right)_{6}(\mathrm{OH})_{2}$ which comprises about $88-90 \%$ of the tissues by volume. The basic structural unit of enamel is enamel prism or rod which consists of several million hydroxyapatite cristallites. ${ }^{12}$ Crystal formation process is slow and numerous different forms of calcium phosphate mineral can be found in enamel. ${ }^{13}$

Sprague Dawley has short duration of pregnancy and is easy to maintain, making this species a suitable subject for embryology research. ${ }^{14}$ Enamel deposition on rat will be observed on day 3 after birth during the late bell stage..$^{15}$ During the late bell stage, the cells of the internal enamel epithelium will differentiate into enamel-forming cells known as ameloblast. These cells go through a series of life cycle from presecretory, secretory, transition, maturation, and post-maturation stage. After the secretion of organic matrices, enamel mineralization will start in the presence of calcium. ${ }^{12}$ This study aimed to determine the effect of nano calcium supplementation during pregnancy on enamel development.

\section{MATERIALS AND METHODS}

This research has been reviewed and approved by the Ethical Committee of the Faculty of Dentistry with Ethical Clearance Letter No. 001261/KKEP/FKG-UGM/EC/2017. In this study, nine 3-month-old female Sprague Dawley were mated with one male Sprague Dawley and divided into three groups: group A was treated with nano calcium supplement (Nature's Health Nano Calcium $\left.{ }^{\circledR}\right)$, group B was treated with micro calcium (Calporosis $\AA$ ), and group C was treated with distilled water.

The pregnancy was checked through the development of vaginal plug and vaginal swab examination using light microscope. This examination was conducted to confirm sperms. The day of sperm identification was marked as day 0 of pregnancy.

The treatment started on day 1 of pregnancy through intragastric administration method. The dose of calcium administered for group A and group $B$ was determined based on USA National Research Centre calcium diet recommendation for pregnant rat with a dose of $252 \mathrm{mg} /$ day per 250-300 gram bodyweight. The treatment was conducted from day 1 of pregnancy to day 1 of birth. Pups were sacrificed on day 1 after birth and the mandibles of 6 pups from each group were collected and immersed in $4 \%$ formaldehyde solution in PBS.

The specimens were then dehydrated using alcohol. Clearing of the specimens was performed using xylol. Before this study, a pilot study was conducted to predict the total length of the molar and to ensure the area where the sections were obtained from each subject is equal.

After embedding, the specimens were cut at $6 \mu \mathrm{m}$ in the midline of the first right molar. During the cutting of the paraffin blocks, the sections were collected sequentially following stereological protocol from the beginning of the tooth buds to the last section of it. The location for the examination of enamel deposition was in the middle of mandibular right first molar, linear to sagittal plane.

The paraffin sections were mounted on glass slides and stained with hematoxylin and eosin. Examination of the mandibular right first molar was conducted using light microscope. The enamel deposition was measured using Optilab Image Raster $\AA$ in three areas on each cusp (Figure 1). The data collected from Group A and B were then analyzed using t-test.

\section{RESULTS}

Histological section of the mandibular right first molar on Sprague Dawley newborn pups showed that enamel was observed on day one after birth but only in the groups treated with nano calcium and micro calcium (Figure 2). Enamel was found on all the 6 pups in group $A$ which were treated with nano calcium and on 5 pups in group $B$ which 
were treated with micro calcium. No enamel was observed in group $\mathrm{C}$.

Enamel deposition was observed and its thickness was measured using Optilab Image Raster ${ }^{\circledR}$. Data collected from group A and group B were shown on Figure 3. The results for normality and homogeneity test showed that the data of enamel thickness on this study were normally distributed and homogeneous $(p>0.05)$. T-test statistical analysis showed that the mean difference between the two groups was significant $(p<0.05)$.

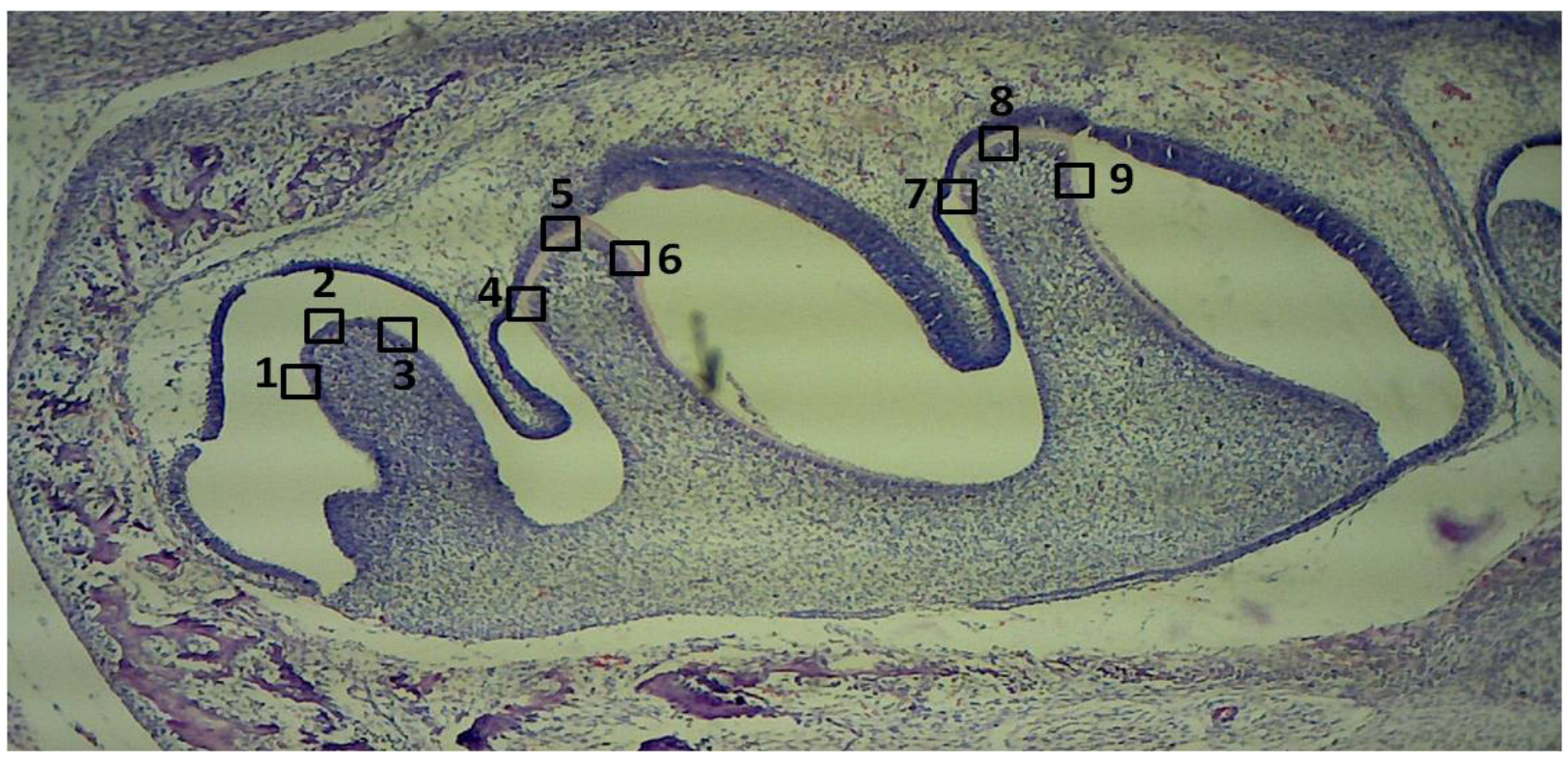

Figure 1. Sprague Dawley's mandibular first molar on day 1 after birth. The tooth at the bell stage and the areas marked as the points where enamel deposition measurements were conducted
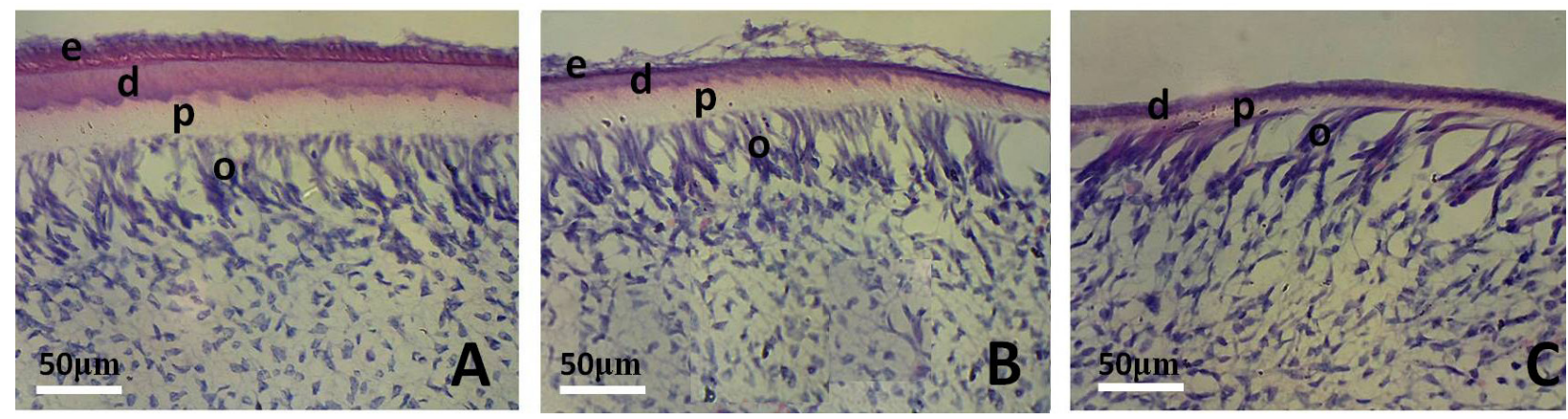

Figure 2. Histological section of Sprague Dawley's mandibular left first molar on day 1 after birth. Stained using hematoxylin and eosin, dentin (d) was observed in group treated with nano calcium (A), micro calcium (B), and negative control (C). Enamel (e) was only observed in group $A$ and $B, p=$ predentin, $o=$ odontoblast 


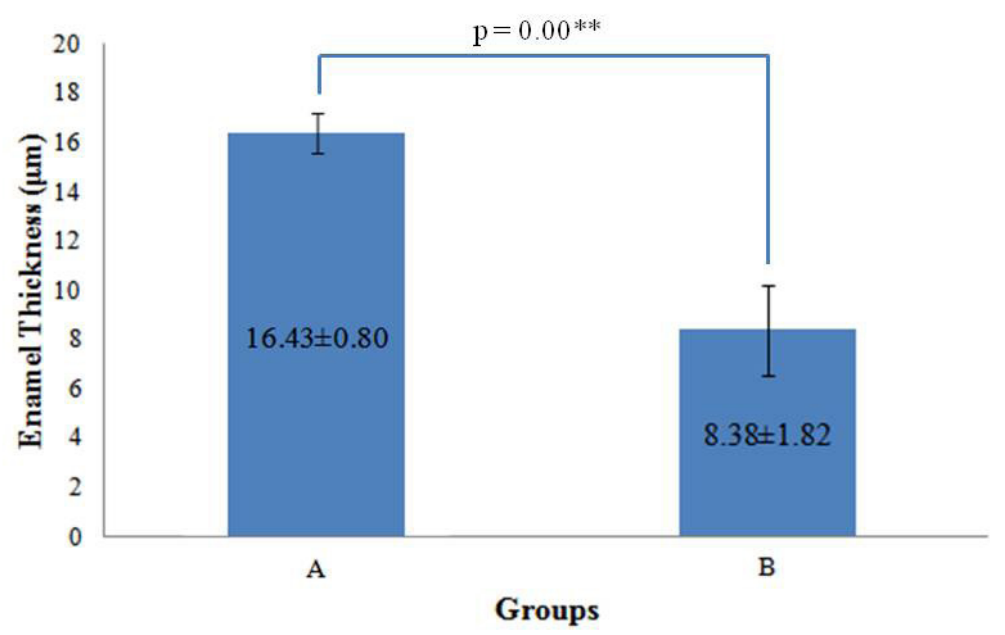

Figure 3. Mean and standard deviation of Sprague Dawley's enamel thickness in groups treated with nano calcium (A) and micro calcium (B)

\section{DISCUSSION}

In this study, enamel was observed in group $A$ and $B$ which were treated with nano calcium and micro calcium. This result was in accordance with previous theory about the effect of supplementation during pregnancy on tooth development. ${ }^{16}$ As a mineral needed during hard tissue mineralization in the body, deficiency of calcium leads to hypomineralization and enamel hypoplasia. ${ }^{12,16}$ Calcium acts as the second messenger which regulates cellular activities and it has been linked to some signaling pathways during tooth development. ${ }^{17,18}$

The calcium ions generated from nano calcium that were fed to Sprague Dawley then spread in the body through blood circulation and helped the mineralization in dental hard tissue. According to a previous study, the number of calcium ions released by nano calcium can be twice or three times higher than those by micro calcium. ${ }^{7}$ Hence calcium ions released by nano calcium supplement may act as a stimulator during amelogenesis.

In this study, on day 1 after birth enamel was only observed in the groups treated with nano calcium and micro calcium. This condition is caused by calcium supplementation during pregnancy which acts as one of the main stimulators during the development of hard tissue in the body. Calcium is known as the second messenger which regulates cellular activities and has been linked to some signaling pathways during tooth development. 17,18
The formation of enamel requires large quantities of calcium ions which travel through extracellular and transcellular routes. ${ }^{12,19}$ In the body there are a number of possible sources for calcium that will mineralize enamel matrix. The precise pathway is still unclear but mainly calcium reaches the matrix via enamel organ. Calcium may flow passively from high concentrations in blood plasma to low concentrations in enamel matrix. ${ }^{12}$

As one of the most abundant elements in enamel, calcium has a critical role during the development of this tissue. Ameloblasts are the cells responsible for regulating enamel matrix deposited during amelogenesis and the transport of calcium ions in mineralization areas. These cells form a barrier to control the amount of calcium deposited in enamel layer and act as a regulator during mineralization process and also protect tissues from toxicity caused by high concentrations of calcium ions in mineralization areas. ${ }^{13,19}$

According to a previous study, ameloblasts have been known to express $\mathrm{Ca}^{2+}$ binding proteins in its cytoplasm and endoplasmic reticulum. ${ }^{19}$ When ameloblasts shift from presecretory to secretory stage, these cells will produce a vesicle which at first will appear at the distal end. This vesicle will be discharged into extracellular space as organic matrix at the end of the cell and between cell membranes. Within this organic matrix, the initial hydroxyapatite crystals appear almost immediately 
before the matrix's thickness reaches $50 \mu \mathrm{m}$. This explains why a zone of unmineralized matrix like predentin in dentin is never seen in enamel. ${ }^{12}$

The first deposited enamel is low in mineral content but has high water and protein content. The process to complete enamel mineralization process is called maturation. This process is carried out by ameloblast which has changed into its transition stage..$^{13}$ In this stage, the secretion of enamel has stopped and ameloblast starts to undergo some changes in height, number, and also morphology as it loses its secretory extension or Tomes' process. Half of the total number of ameloblasts undergoes apoptosis and the remaining ameloblasts also lose organelles associated with protein synthesis through autophagocytosis. At the final stage of transition phase, ameloblast will form basal lamina which covers immature enamel and the cells are attached to it through hemidesmosome. ${ }^{12}$

In total, about of $90 \%$ of protein found in young enamel is amelogenins. The other $10 \%$ is non amelogenins such as enamelin and tuftelin. During the maturation period, amelogenins are removed. Another characteristic of maturation period is an increase in the width and thickness of enamel crystals. Calcium and phosphate ions are added into enamel matrix which increase enamel crystal size. ${ }^{12,13}$ Enamel hardens during maturation stage and this change in physicochemical properties is related to the growth of crystals. ${ }^{20}$

After maturation period is complete, enamel has changed from a watery tissue with high protein and low mineral content into the hardest tissue in the body consisting of hydroxyapatite crystals. ${ }^{12,20}$ This process takes place after calcium ion deposition regulated by ameloblast. Specific initiator for mineralization in enamel has not been identified but it has been suggested that crystal growth is controlled by tuftelin as one of the nonamelogenins proteins found in enamel. ${ }^{12}$

In this study, fast enamel deposition on calcium treated group indicated the involvement of calcium during tooth development. Calcium is one of the second messengers which can regulate cellular activity and is linked to some signaling pathways related to tooth development. ${ }^{17,18}$ As a second messenger, calcium ions induce cellular motility and proliferation. The development of enamel itself is a complex mechanism which involves the interaction of oral epithelium and mesenchyme. The process starts when mesenchyme tissue migrates toward oral epithelium and in contact with basal lamina. ${ }^{12}$

The signal produced by tyrosine receptor kinase (TRK) induces the development of inositol triphosphate $\left(\mathrm{IP}_{3}\right)$ which then activates inositol triphosphate receptor $\left(I_{3} R\right)$. This activation induces the release of calcium ions from reticulum endoplasm and causes the elevation of $\mathrm{Ca}^{2+}$ pulse inside the cell. The $\mathrm{Ca}^{2+}$ pulse will activate myosin light chain kinase (MLCK) which causes myosin II phosphorylation and induces the development of focal adhesion or protein complex to facilitate cell migration. ${ }^{21}$

The migration of mesenchyme tissue toward oral epithelium induces the differentiation of outer mesenchymal cells of the dental papilla into odontoblast which then secretes the first matrix of predentin. The cells in internal enamel epithelium, which now are called pre-ameloblasts, release enzymes to degrade basal lamina then resorb the degradation products. After the degradation of basal lamina, pre-ameloblast and odontoblast will be in contact for a while and this allows for cellular communication between these layers. Signaling molecules produced by these layers can induce the differentiation of dental mesenchyme and oral epithelium. BMP and FGF from dental mesenchyme induce the differentiation of oral epithelium into ameloblast while Wnt, Runx-2, and TGF- $\beta$ from oral epithelium layer are capable of inducing the differentiation of dental mesenchyme into odontoblast. ${ }^{22}$ Upon the secretion of predentin, the basal lamina separating odontoblast and from internal enamel epithelium completely disappear and the internal enamel epithelium starts to differentiate into pre-ameloblast which then undergoes a series of life stages. ${ }^{12,13}$

In this study, the nano calcium supplement used was a mixture of nano calcium carbonate and vitamin $D$ since a pure nano calcium supplement has not been developed. As a comparison, a mixture of micro-sized calcium carbonate with 
vitamin D was used. The addition of vitamin D into calcium supplementation is carried out to increase the absorption of calcium ion since vitamin $D$ in its active form, $1,25(\mathrm{OH})_{2} \mathrm{D}_{3}$, is a stimulator for calcium absorption in the body by regulating mRNA level of vitamin D-dependent calcium-binding proteins (calbindin-D). ${ }^{23}$ The active form of vitamin D or also known as calcitriol can increase calcium cellular transport by facilitating the diffusion of calcium ion from intestinal epithelial apical calcium channel, activation of transient receptor potential vanilloid type 6 (TRPV6), and entrance of calcium ion through intestinal plasma membrane pump PMCA1b. ${ }^{24}$

The deposition of enamel in this study was measured using Optilab Image Raster®. This method is prone to bias when the slicing of paraffin section is not linear to sagittal plane due to the placement of specimen during embedding. The most ideal measurement for enamel deposition using histological method is through the determination of enamel volume using stereological analysis method (Cavalieri's Principle). However, for this study which was done on the first day after birth, the determination of area where the enamel was already deposited to choose the area for stereological sequence slicing was an uphill task. Therefore, a more detailed study on enamel volume and structure is needed to confirm the effect of nano calcium supplementation on enamel development.

\section{CONCLUSION}

It can be concluded that the administration of nano calcium during pregnancy leads to rapid enamel deposition on Sprague Dawley pups.

\section{ACKNOWLEDGMENTS}

This work was supported by the Faculty of Dentistry Universitas Gadjah Mada through Dana Masyarakat Research Funding No. 4646/KG/PP/2017. Our sincere gratitude goes to Mr. Sutari and Mr. Wasino from UGM Animal Experiment Unit and Mr. Yohanes Suhardi from Histology and Cellular Biology Laboratory Faculty of Medicine UGM.

\section{REFERENCES}

1. Vavrusova M, Skibsted LH. LWT - Food Science and Technology Calcium nutrition. Bioavailability and forti fi cation. LWT - Food Sci Technol. 2014; 59: 1198-1204.

2. Gharibzahedi SMT, Jafari SM. The importance of minerals in human nutrition: Bioavailability, food fortification, processing effects, and nanoencapsulation. Trends Food Sci Technol. 2017; 62(2017): 119-132.

3. Kardos TB, Hunter AR, Hanlin SM, Kirk EE. Odontoblast differentiation: a response to environmental calcium? Endod Dent Traumatol. 1998; 14(3): 105-111.

4. Hirayama S, Komine C, Takahashi C, Matsui $\mathrm{S}$, Matsushima K. Effects of calcium carbonate on odontoblast differentiation and calcification ability of human dental pulp cells. J Oral Tissue Engin. 2013; 11(2): 123-134.

5. Chaudhry $Q$, Scotter M, Blackburn J, Ross $B$, Boxall A, Castle L, et al. Applications and implications of nanotechnologies for the food sector. Food Addit Contam Part A Chem Anal Control Expo Risk Assess. 2008; 25(3): 241-258.

6. Rizvi SSH, Moraru $\mathrm{Cl}$, Bouwmeester $\mathrm{H}$, Kampers FWH. Nanotechnology and Food Safety. In: Boisrobert CE, Stjepanovic A, Oh $S$, Lelieveld HLM, editors. Ensuring Global Food Safety: Exploring Global Harmonization. Amsterdam: Academic Press; 2010.

7. Jeong MS, Cho HS, Park SJ, Song KS, Ahn KS, Cho M-H, et al. Physico-chemical characterization-based safety evaluation of nanocalcium. Food Chem Toxicol. 2013; 62(2013): 308-317.

8. Hagens WI, Oomen AG, De Jong WH, Cassee FR, Sips AJ. What do we (need to) know about the kinetic properties of nanoparticles in the body? Regul Toxicol Pharmacol. 2007; 49(3): 217-229. 
9. De Jong WH, Hagens WI, Krystek P, Burger MC, Sips AJ, Geertsma RE. Particle sizedependent organ distribution of gold nanoparticles after intravenous administration. Biomaterials. 2008; 29(12): 1912-1919.

10. Buchowski MS. Calcium in the context of dietary sources and metabolism. In: Preedy VR, editor. Calcium: Chemistry, Analysis, Function, and Effects. Cambridge: The Royal Society of Chemistry; 2016.

11. Ziegler J, Mobley CC. Pregnancy, child nutrition, and oral health. In: Touger-Decker R, Mobley C, Epstein JB, editors. Nutrition and Oral Medicine. London: Humana Press; 2014.

12. Berkovitz BKB, Holland GR, Moxham BJ. Oral anatomy, histology, and embryology. 4th ed. London: Mosby Elsevier; 2009.

13. Berkovitz BKB, Moxham BJ, Linden RWA, Sloan AJ. Master dentistry volume three: oral biology. Third Edit. London: Churchill Livingstone Elsevier; 2011.

14. Otto GM, Franklin CL, Clifford CB. Biology and diseases of rats. In: Fox JG, Anderson LC, Otto GM, Pritchett-Corning KR, Whary MT, editors. Laboratory Animal Medicine. 3rd ed. Amsterdam: Academic Press; 2015.

15. Gaete M, Lobos N, Torres-Quintana M. Mouse tooth development time sequence determination for the ICR/Jcl strain. J Oral Sci. 2004; 46(3): 135-141.

16. Ziegler J, Mobley CC. Pregnancy, child nutrition, and oral health. In: Touger-Decker R, Mobley CC, Epstein JB, editors. Nutrition and Oral Medicine. New York: Springer Science; 2014.
17. Ornitz DM, Itoh $\mathrm{N}$. The fibroblast growth factor signaling pathway. WIREs Dev Biol. 2015; 4: 215-266.

18. Zheng L, Ehardt L, McAlpin B, About I, Kim $D$, Papagerakis $S$, et al. The tick tock of odontogenesis. Exp Cell Res. 2014; 325: 83-89.

19. Nurbaeva MK, Eckstein M, Concepcion AR, Smith CE, Srikanth S, Paine ML, et al. Dental enamel cells express functional SOCE channels. Sci Rep. 2015; 5(15803): 1-10.

20. Nanci A. Ten Cate's Oral Histology. 9th ed. Missouri: Elsevier; 2017.

21. Tsai F-C, Kuo G-H, Chang S-W, Tsai P-J. $\mathrm{Ca} 2+$ signaling in cytoskeletal reorganzation, cell migration, and cancer metastasis. BioMed Res Int. 2015; 2015: 1-13.

22. Matalova E, Lungova V, Sharpe $P$. Development of tooth and associated structures. In: Vishwakarma A, Sharpe P, Shi $\mathrm{S}$, Ramalingam M, editors. Stem Cell Biology and Tissue Engineering in Dental Sciences. 1st ed. Cambridge: Academic Press; 2014.

23. Li YC, Pirro AE, Demay MB. Analysis of vitamin D-dependent calcium-binding protein messenger ribonucleic acid expression in mice lacking the vitamin $\mathrm{D}$ receptor. Endocrinology. 1998; 139(3): 847-851.

24. Christakos S, Dhawan P, Porta A, Mady LJ, Seth T. Vitamin D and intestinal calcium absorbtion. Mol Cell Endocrinol. 2011; 347(1-2): 25-29. 